\title{
Impact of prophylaxis with cotrimoxazole on malaria parasitaemia, PCV and CD4+ count in HIV-infected pregnant women in Jos, Nigeria
}

\author{
Ali MA ${ }^{1}$, Agbo EB ${ }^{2}$, Suleiman $\mathrm{MM}^{2}$, Oguche $\mathrm{S}^{3}$, Musa J ${ }^{4}$, Okojokwu $\mathrm{OJ}^{1}$, Anejo-Okopi JA ${ }^{1}$ and Lar PM ${ }^{1}$ \\ ${ }^{1}$ Department of Microbiology, Faculty of Natural Sciences, University of Jos, Nigeria \\ ${ }^{2}$ Department of Biological Sciences, Abubakar Tafawa Balewa University, Bauchi, Nigeria \\ ${ }^{3}$ Department of Paediatrics, Faculty of Medical Sciences, University of Jos, Nigeria \\ ${ }^{4}$ Department of Obstetrics and Gynaecology, Faculty of Medical Sciences, University of Jos, Nigeria
}

\begin{abstract}
The effect of prophylaxis with Cotrimoxazole (CTX) against malaria parasitaemia and other pregnancy outcomes among HIV-infected pregnant women in Jos was investigated. Peripheral blood from study women was used to prepare thin and thick blood smears for the identification and estimation of malaria parasitaemia as well as immunological and haematological investigations. Sulfadoxine pyrimethamine (SP) was used as control, being the standard used for prophylaxis against malaria in pregnant women. Result shows that Prevalence of malaria infection was reduced from 34.1-7.2\% and from 25-10\% among group A and B respectively. Mean parasitaemia was reduced from 1984.76 asp/ $\mu$ to $1000.00 \mathrm{asp} / \mu \mathrm{l}$ and from $1960.38 \mathrm{asp} / \mu$ to 1118.18 asp/ $\mu$ for CTX an SP respectively. Mean packed cell volume (PCV) was reduced from 33.09-33.02\% with CTX and from 33.11-32.90\% with SP. Mean CD4+ count increased from 223.55 cells/ $\mu$ l to 300.54 cells/ $\mu 1$ with CTX but decreased from 570 cells/ $\mu 1$ to 536.4 cells/ $\mu 1$ with SP. Prophylaxis with CTX is associated with $89 \%$ reduction in parasitaemia, with immunological but no haematological benefits, while prophylaxis with standard $\mathrm{Sp}$ is associated with $76 \%$ reduction in malaria parasitaemia with neither immunological nor haematological benefits. There was no statistical difference between the two drugs throughout the study. The use of cotrimoxazole for antimalarial prophylaxis among HIV-infected pregnant women is strongly supported but with close monitoring of their PCV so as to detect and treat any possible anaemia.
\end{abstract}

\section{Introduction}

Malaria remains a major global health threat with substantial burden on sub-Saharan Africa where an estimated $90 \%$ of all malaria deaths occur particularly among pregnant women and children under 5 years of age [1]. Co-infection of HIV and Malaria makes malaria in pregnancy more severe by impairing the ability of women to control the illness $[2,3]$ owing to the effect of HIV in destroying the natural immunity against malaria.

Intermittent preventive treatment (IPT) with anti-malarial drugs, has been proven to be an effective means of controlling malaria in endemic countries, with Sulfadoxine Pyrimethamine (SP) being the drug of choice among pregnant women [4]. The WHO [5] had however advocated for the use of Cotrimoxazole, a broad-spectrum antibiotic consisting of Sulfamethoxazole and Trimethoprim, commonly used as prophylactic agent against opportunistic infections in HIVinfected individuals, for antimalarial prophylaxis in pregnancy. This is thought to minimize toxicity effect arising from concurrent use of the two drugs which are both sulfur-based. There is paucity of data from the West African region on the effectiveness of Cotrimoxazole in reducing malaria parasitaemia among HIV-infected pregnant women. Such evidence-based information is essential for safe and effective management and prevention of malaria among this population.

Our specific objectives were to; Determine the prevalence and intensity of malaria parasitaemia among HIV-infected pregnant women before and after antimalarial prophylaxis with Cotrimoxazole versus SP in Jos, Plateau state. Determine the Packed Cell Volume (PCV) of HIV-infected pregnant women before and after prophylaxis with Cotrimoxazole as compared with SP in Jos, Nigeria. Determine the Immunological characteristics (maternal CD4+) of HIV-infected pregnant women before and after prophylaxis with Cotrimoxazole versus Sp among the study population

\section{Methodology}

\section{Study sites and population}

The study was conducted in three different sites within Jos metropolis; Faith alive Foundation Hospital (FAFH), Bingham University Teaching Hospital (BHUTH) and Plateau State Specialist Hospital (PSSH), all of which have comprehensive HIV care centres. Plateau State Specialist Hospital (PSSH) and BHUTH are Tertiary Health Institutions while Faith Alive Foundation Hospital is a nonGovernmental Hospital that cares for people living with HIV, in Plateau state and environs. A total of $235 \mathrm{HIV}$-infected pregnant women were recruited for the study from these Hospitals after obtaining ethical permission from the Committee on Health Research Ethics of the Bingham University Teaching Hospital Jos, and informed written consents of the study subjects.

\section{Study design}

Figure 1 shows the flow diagram of the study was conducted. Two hundred and thirty-five (235) eligible HIV-infected women who

Correspondence to: Ali MA, Department of Microbiology, Faculty of Natural Sciences, University of Jos, Nigeria, Tel: 08036914138; E-mail: alimurna@yahoo.com

Received: November 21, 2017; Accepted: December 05, 2017; Published: December 08, 2017 
235 women who fulfilled the inclusion criteria and gave

consents, enrolled into the study from FAFH, BHUTH and
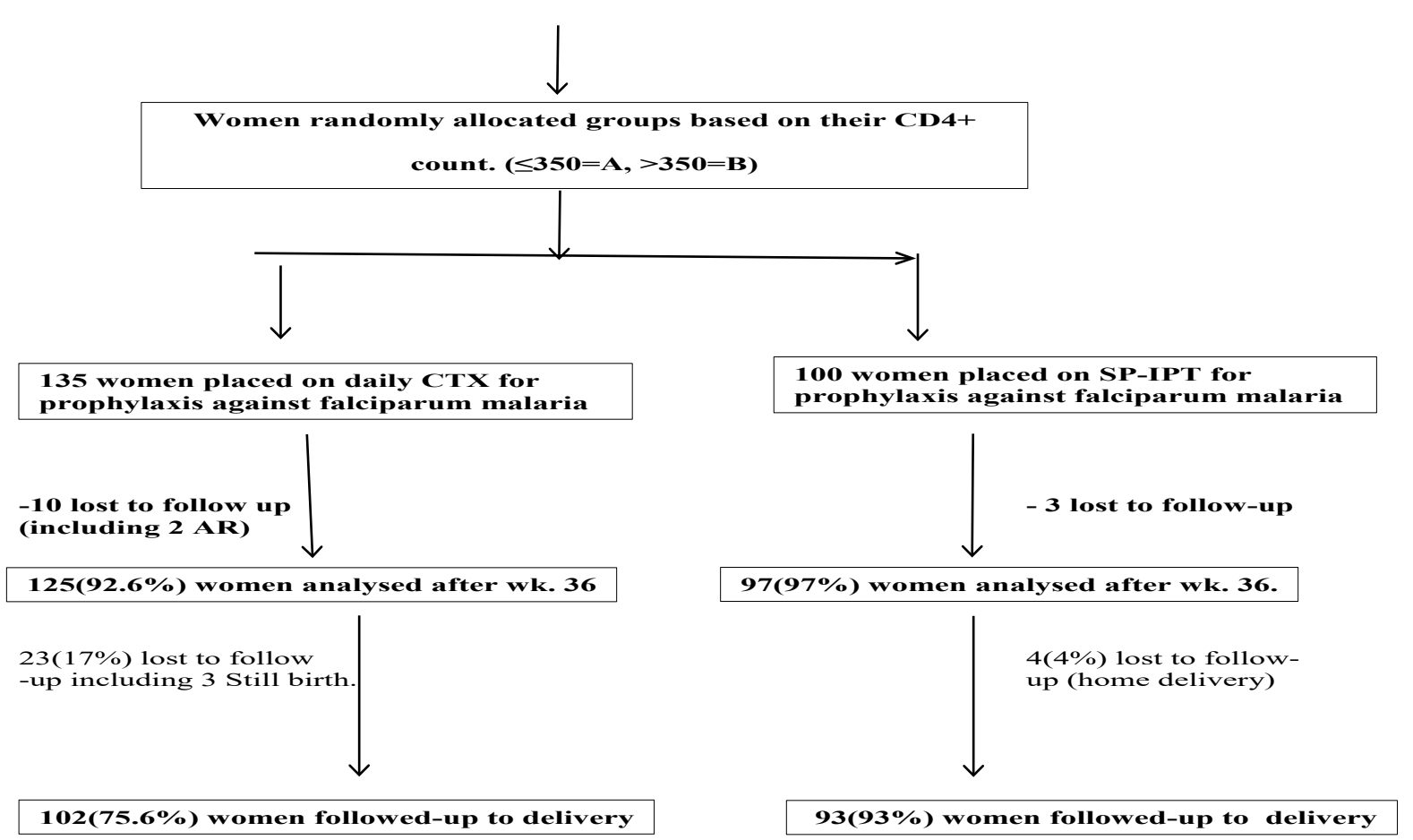

Figure 1. Flow diagram of activities involved in the study of the effect of prophylaxis with CTZ against falciparum malaria parasitaemia in HIV-infected pregnant women in Jos (CTX: Cotrimoxazole; IPT-SP: Intermittent preventive treatment with Sulfadoxin Pyrimethamine; AR: Adverse drug reaction)

fulfilled the inclusion criteria and consented to the study were enrolled into either Cotrimoxazole (CTX) or Sulfadoxine Pyrimethamine (SP) treatment groups (A \& B respectively) based on their CD4+ count. The study group (A), comprised those with CD4+ count of 350 cells/ $\mu \mathrm{l}$ or less, and accounted for 135 of the study population, while group B comprises of those with CD4+ count greater than 350 cells/ $\mu$ land comprises of 100 pregnant women. While group A were administered Cotrimoxazole (CTX), their group B counterparts were given intermittent preventive treatment with Sulfadoxine-Pyrimethamine (SP), according to the WHO guideline [5]. Since SP is generally being used as the standard care against malaria in pregnancy in the respective Hospitals as also advocated by the WHO [4], it was used as a control in this study.

Following enrolment, structured case record forms were used for the purpose of collecting the biodata as well as obstetric and other socio-demographic information of the participants. Five millilitres $\left(5 \mathrm{~cm}^{3}\right)$ of blood was collected through venepuncture for PCV, CD4 count and malaria parasites (MP) investigations. The blood was poured into EDTA bottles and processed immediately. Where immediate processing was not possible, samples were kept in the refrigerator at $4^{\circ} \mathrm{C}$ and used within $4 \mathrm{hrs}$. For the purpose of this research, no personal identifiers (names, identity numbers, address etc.) were used on the blood samples of participants. Instead, coded numbers were used to ensure anonymity. Participants in the experimental group (A) were administered $960 \mathrm{mg}$ Cotrimoxazole to be taken daily for prophylaxis against malaria and other opportunistic infections. Those in the control group (B) were given three doses of Sulfadoxine Pyrimethamine (500 $\mathrm{mg}$ of sulfadoxine $+25 \mathrm{mg}$ pyrimethamine, with 3 tablets given at each dose), $1^{\text {st }}$ at week $13-20,2^{\text {nd }}$ at week 21-28 and the $3^{\text {rd }}$ at week $28-36$ ).
Addresses and GSM numbers of participants were collected for followups and other informal interactions. Participants were then followedup to delivery.

At week 36, peripheral venous blood was again collected for the determination of $\mathrm{CD} 4+$ count, presence and intensity of plasmodium parasites and PCV. Use of insecticide-treated bed nets (ITNs) by participants was also ascertained at this point, which also marked the end of prophylaxis.

\section{Parasitological investigations}

Both thin and thick blood smears were prepared for the screening and identification of malaria parasites according to the methods described by WHO [6].

The diagnosis of malaria was based on the identification of asexual stages of Plasmodium on the thick blood smears, while thin blood smears were used to identify species of Plasmodium. Plasmodium parasite density was determined by counting the number of asexual parasites against 200 leucocytes on the thick blood film and converted to parasites per $\mu \mathrm{l}$ using an assumed total white blood cell (WBC) count of $8,000 / \mu \mathrm{l}$. Blood films were declared negative or insignificant if no parasite was seen after viewing $500 \mathrm{WBC}$ [7].

Parasite density (Parasitaemia) $\frac{(x) \times 8000}{(Y)}$

Where; $\mathrm{X}=$ Number of parasites counted, $8000=$ standard WBC count

$\mathrm{Y}=$ Number of White blood cells count. (WBC)

All slides read, were confirmed by a microscopist with the roll 
back malaria program. Where there were discrepancies, a second microscopist was involved for the final verdict. Parasite density was classified according to the methods described by Trape [7] and Boisier, et al. [8].

Percent (\%) reduction in Malaria parasitaemia was determined as shown in equation 2 below

$$
\operatorname{MpR}(\%)=\frac{\% \text { Mpbf }-\% \text { Mpaf }}{\% \text { Mpbf }} \times 100
$$

Where $\% \mathrm{MpR}=$ Per cent malaria parasite reduction

$\% \mathrm{Mpbf}=$ Per cent malaria parasitaemia before prophylaxis

$\% \mathrm{Mpaf}=\mathrm{Per}$ cent malaria parasitaemia after prophylaxis Determination of $\mathrm{CD}^{+}$cell count

The CD4 T lymphocytes count was determined according to the method described by WHO [9] as follows:

\section{Determination of CD4+ count}

i) 20 microlitre whole blood (EDTA as anticoagulants) was added into a partec test tube properly labelled with the patients' code for proper identification

ii) 20 microlitre $(\mu \mathrm{l})$ of $\mathrm{CD} 4 \mathrm{mAb} \mathrm{M}$ antibodies was added and mixed properly.

iii) Mixture was incubated for 15 mins at room temperature protected from light.

iv) This was followed by addition of 800 microlitres of non- lyse buffer and shaken gently without allowing for bubbles to form.

v) Mixture was then analysed on a partec device.

vi) CD4 cells were measured and counted using the flow cytometric analyser in a partec flow cytometer (Cyflow counter) with an excitation light source of $488 \mathrm{~nm}$ or $532 \mathrm{~nm}$ (blue or green solidstate laser). The dilution factor was 42 .

\section{Determination of Packed Cell Volume (PCV)}

The PCV of study population was determined using the capillary tube method and read in a Microhaematocrit reader as described by Bull, et al. [10].

\section{Data analysis}

Data generated from the study were analysed using SPSS statistical software for Windows 11.0 (SPSS Inc. USA). Occupation, educational status and other categorical variables were compared using chi square to determine any association between the various outcomes in the two groups. Bar charts were used for graphical display of categorical variables. Regression analysis was used to determine the association of drug exposure with Parasitological, Immunological and Haematological parameters. Impact of other confounding factors was ascertained using the multivariate analysis and a $5 \%$ level of probability $(\mathrm{P}<0.05)$.

\section{Results and discussions}

\section{Malaria infection among study population}

Mean (Range) parasitaemia at enrollment was 1984.76 (1200-3800) asp/ $\mu \mathrm{l}$ and 1960.38 (1200-5050) asp/ $\mu$ l for groups A and B respectively. Prevalence of malaria infection was significantly $(\mathrm{P} \leq 0.05)$ higher among women who took CTX [46 (34.1\%)] than those who took SP [25 (25\%)] before prophylaxis. However, prophylaxis with CTX reduced more parasitaemia compared to SP [9 (7.20) vs $10(10.31)]$, but the difference was not significant statistically $(\mathrm{P} \geq 0.05)$ as shown on Table 1. Our result is similar to earlier reports by Houmsou, et al. [11], in which pregnant women with low CD4+ counts (201-500 cells/ $\mu \mathrm{L}$ ) were significantly and four times more infected than those with higher CD4+ counts. This is expected since those in group A had lower immunity compared to those in group B, as also indicated by their low $\mathrm{CD} 4+$ count. Very low immunity is said to allow for easy establishment and multiplication of infectious agents.

The parasite density was generally low to moderate (500-5050 asp/ $\mu \mathrm{l})$. This may be partly attributed to the reconstitution of their immune system, resulting from the use of HAART.

Statistical summary of malaria infection in relation to demographic and other base-line characteristics of study population is as shown on Table 2. There is no significant statistical difference in malaria infection in relation to patients' demographic characteristics throughout the study. This shows that malaria infection affects HIV-infected pregnant women regardless of their demographic or obstetric status. Coinfection of malaria and HIV is said to impair the woman's antimalarial immunity [2], known to develop with age in areas with stable malaria transmission so that infection occurs regardless of patient's demography.

The use of insecticide treated bed nets (ITBNs) was significantly associated with malaria parasitaemia in this study $(\mathrm{P}=0.02$ and 0.012 before and after prophylaxis with CTX respectively). Although malaria infection increases with duration of HIV, such difference was not significant statistically $(\mathrm{P} \geq 0.05)$. Similarly, malaria infection did not vary significantly with duration of ARV usage throughout the study $(\mathrm{P} \geq 0.05)$ as shown in the Figure. Although malaria infection rates varied among women taking the different ARV regimens, such differences were not statistically significant $(\mathrm{P}>0.05)$.

Multivariate analysis of age, gravidity, duration on ARV \& use of insecticide treated bed nets (ITBNs) revealed that their individual contributions to the overall reduction in peripheral maternal malaria parasitaemia after prophylaxis was not statistically significant as all the regression coefficients were greater than the 0.05 significance level (Figure 2).

\section{Packed cell volume of study population}

The mean PCVs in the two groups are both slightly lower than the normal ranges (36-46\%) for the study population. Mean PCV was reduced from 33.09 to $33.02 \%$ for group A and from 33.11 to $32.9 \%$ among group $\mathrm{B}$, but the difference between the groups is statistically insignificant $(\mathrm{P} \geq 0.05)$.

PCV similar to $33.1 \%$, peviously reported by Panti, et al. [12], but slightly lower than the $34.3 \%$ reported from Coastal Ghana [13]. Differences attributable to the difference in the characteristics of the two populations, since they worked with non-infected pregnant women.

Severe anaemia $(<25 \%)$ was higher among those who had prophylaxis with CTX than those who took SP. This is higher than that reported by Achidi, et al. [14] from Cameroon, Kapito-Tembo, et al. [15] from rural Malawi and Stephens, et al. from Coastal Ghana. However, the low number (6 \& 1 for group A \& B respectively) of women with mild-moderate anaemia in the study is expected, given the high percent reduction in parasitaemia after prophylaxis. Apart from its significant contribution to maternal mortality and both maternal and infant morbidity, anaemia in pregnancy is a risk factor for infant iron deficiency anaemia [16], and it may be associated with adverse behavioral and cognitive development if left unchecked [17] (Figure 3). 


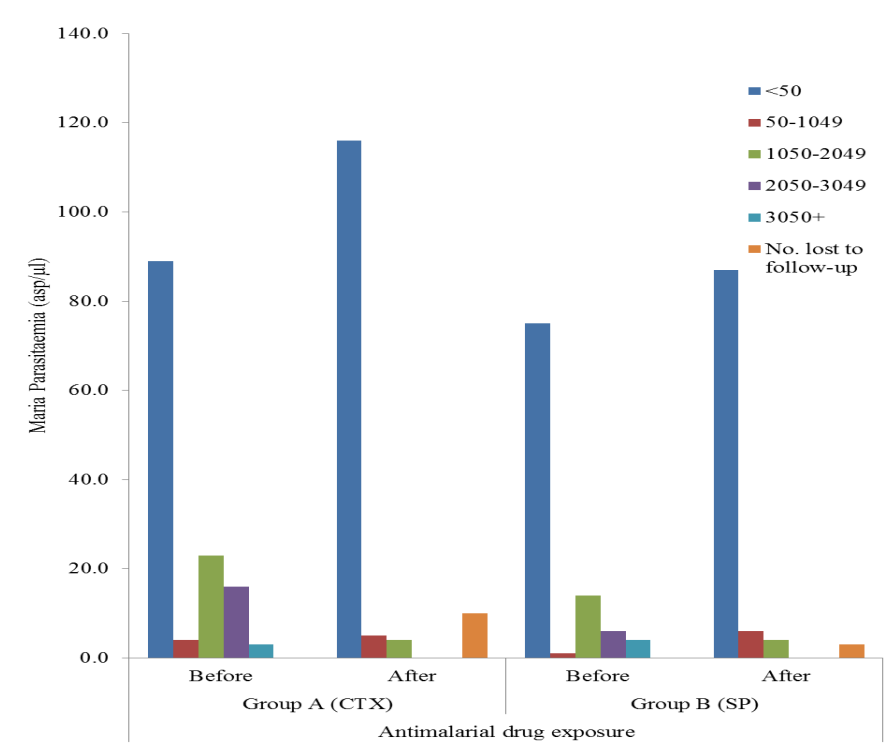

Figure 2. Malaria parasitaemia among HIV-infected pregnant women by antimalarial drug exposure.

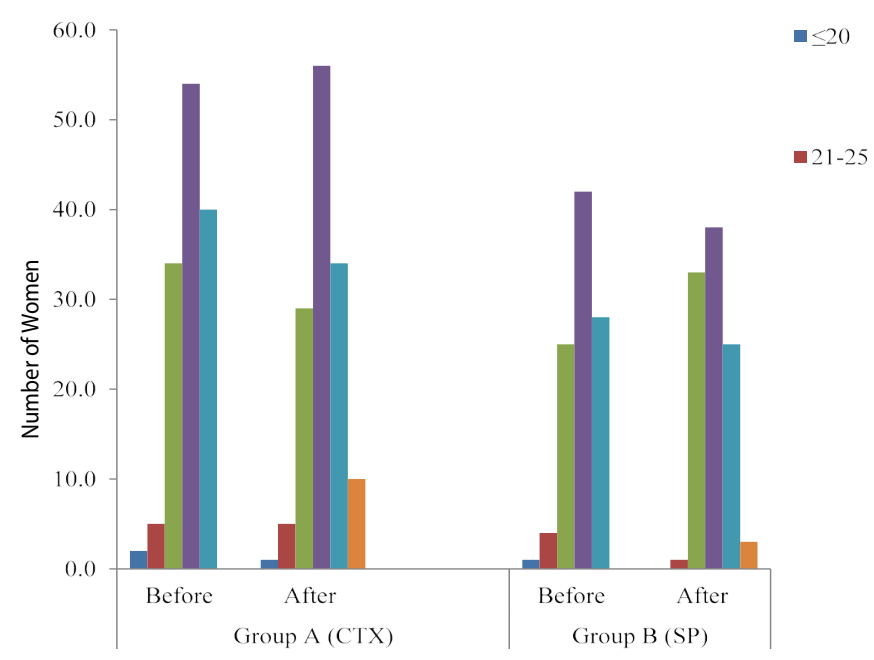

Packed cell volume (PCV) of study population

Figure 3. Packed cell volume (PCV) of study population by antimalaria drug exposure for prophylaxis.

\section{CD4+ count (cells/ $\mu \mathrm{l})$ of study population}

Prophylaxis with CTX associated with slightly but significant $(\mathrm{P}=0.001)$ increases in $\mathrm{CD} 4+$ count. (Mean $\mathrm{CD} 4+$ count increased from 223.55 to 300.54 among group A but decreased from 570 to 536.4 among group B. Only $2(1.6 \%)$ had CD $4+$ count of $\leq 50$ cells/ $\mu$ l, just as the group with $251-350$ cells/ $\mu$ increased to78 (57.8\%). Among group $\mathrm{B}$ however, there were slight but statistically significant $(\mathrm{P}=0.001)$ decreases in CD4+ count as shown in the figure. It is also noteworthy that the lower classes of $\leq 200 \mathrm{cell} / \mu \mathrm{l}$ as well as $201-350 \mathrm{cell} / \mu \mathrm{l}$ that were not found at enrollment, now had up to 3 (3.0\%) and 11 (11.0\%) women after prophylaxis with the standard SP.

Malaria parasitaemia was inversely but significantly associated with CD4+ T cell count. T-cell immunity in HIV-infection is impaired, which is of importance for antimalarial responses. This result is consistent with previous studies $[11,18,19]$.
Table 3 shows the statistical summary of the prophylactic activity of the drug. Parasitaemia was significantly reduced by $89.4 \%$ and $76.0 \%$ ( $\mathrm{P}=0.0000001$ and 0.0001 for $\mathrm{A}$ and $\mathrm{B}$ respectively). PCV was significantly $(\mathrm{P}=0.015)$ reduced by $6.87 \%$ among group $\mathrm{A}$, but the $3.5 \%$ reduction in group $B$ was not significant $(P \geq 0.05)$. There was a significant $(\mathrm{P}=0.00006)$ increase of $24.5 \%$ in CD4+ count among the CTX group, whereas a slight but significant $(\mathrm{P}=0.011)$ decrease of $8.7 \%$ was recorded among those who took SP for prophylaxis. These may be accounted for by the prophylactic activity of the drugs (Figures 4 and 5) [20].

\section{Conclusion and recommendation}

Prophylaxis with CTX was associated with $89 \%$ reduction in parasitaemia, with immunological but no haematological benefits, while Prophylaxis with standard Sp was associated with $76 \%$ reduction in malaria parasitaemia with neither immunological nor haematological benefits. The need to closely monitor women using

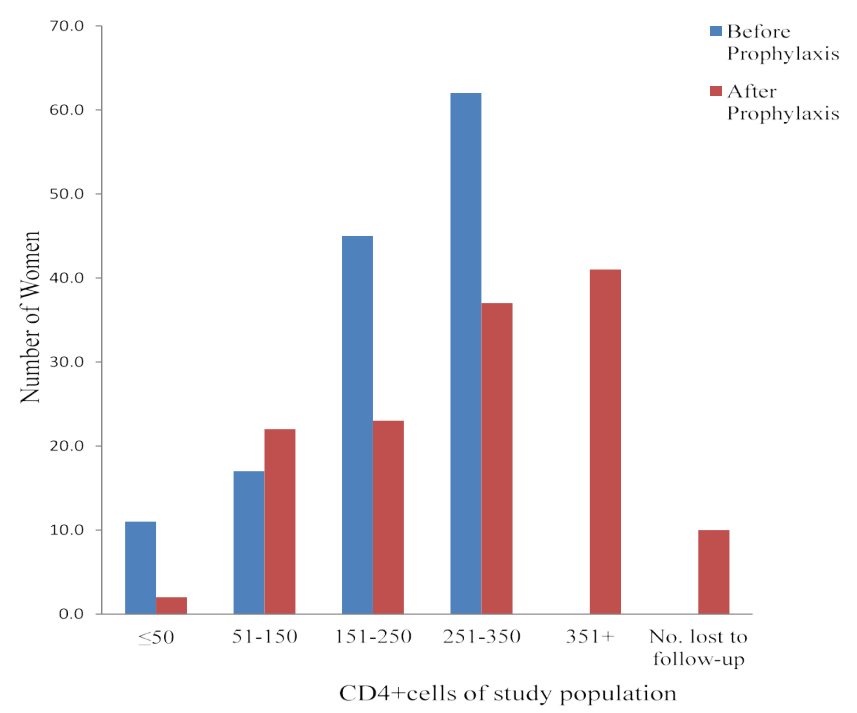

Figure 4. CD4+count of study population Exposed to Cotrimoxazole for prophylaxis

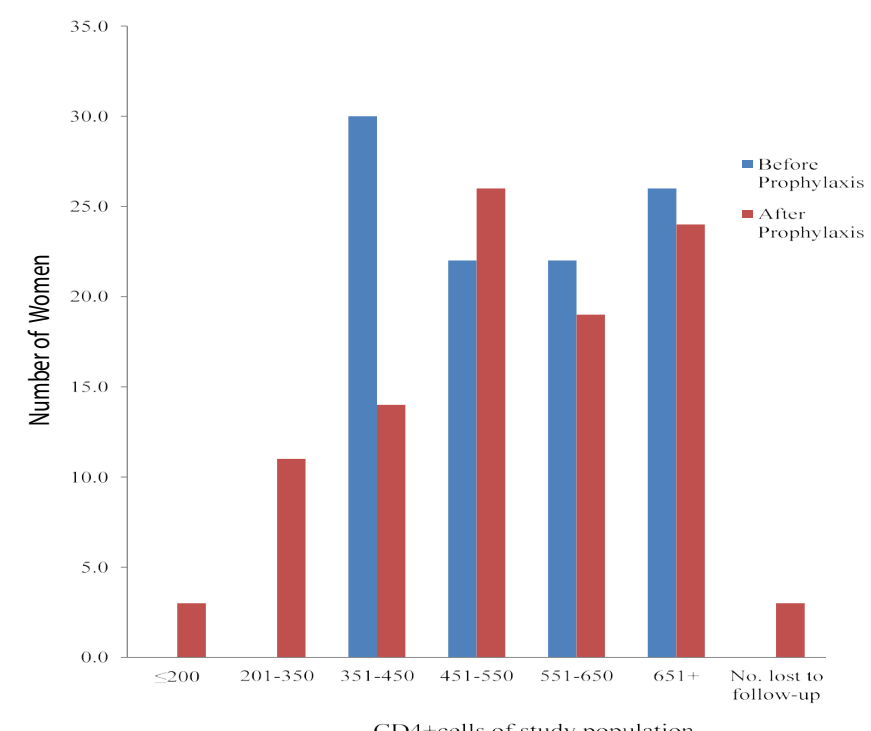

Figure 5. CD4+cells of study population Exposed to Sulfadoxin Pyrimethamine gor antimalarial prophylaxis 
Table 1. Prevalence of malaria parasites before and after prophylaxis ( 36 weeks) among study population.

\begin{tabular}{|c|c|c|c|c|c|c|c|c|c|}
\hline \multirow{2}{*}{ Study group } & \multicolumn{3}{|c|}{ Before prophylaxis } & \multicolumn{4}{c|}{ After prophylaxis } & Loss to follow-up \\
\cline { 2 - 9 } & No. examined & No.+ve (\%) & Prev & No. examined & No.+ve (\%) & Prev. & No. examined \\
\hline Group A (CTX) & 135 & $46(34.07)$ & 19.58 & 125 & $9(7.20)$ & 3.83 & 10 \\
\hline Group B (SP) & 100 & $25(25.00)$ & 10.64 & 97 & $10(10.31)$ & 4.26 & $2(20)$ & 0.85 \\
\hline Total & 235 & 71 & 30.21 & 222 & $19(8.56)$ & 8.09 & 0.43 \\
\hline
\end{tabular}

CTX: Cotrimoxazole; SP: Sulfadoxine pyrimethamine

Table 2. Statistical summary of Malaria infection in relation to demographic and other characteristics of study population.

\begin{tabular}{|c|c|c|c|c|c|c|c|c|}
\hline \multirow[b]{3}{*}{ Parameter } & \multicolumn{4}{|c|}{ Group A: 135} & \multicolumn{4}{|c|}{ Group B: $n=100$} \\
\hline & \multicolumn{2}{|c|}{ Before } & \multicolumn{2}{|c|}{ After } & \multicolumn{2}{|c|}{ Before } & \multicolumn{2}{|c|}{ After } \\
\hline & Number Positive (\%) & P value & Number Positive (\%) & $P$ value & Number Positive (\%) & P value & Number Positive (\%) & $\mathrm{P}$ value \\
\hline Age (yrs) & $46(34.1)$ & 0.148 & $09(7.2)$ & 0.54 & $25(25)$ & 0.08 & $10(10.3)$ & 0.036 \\
\hline Occupation & $46(34.1)$ & 0.613 & $9(7.2)$ & 0.67 & $25(25)$ & 0.417 & $10(10.3$ & 0.1 \\
\hline Educational Status & $46(34.1)$ & 0.157 & $09(7.2)$ & 0.34 & $25(25)$ & 0.932 & $10(10.3)$ & 0.577 \\
\hline Marital Status & $46(34.1)$ & 0.712 & $09(7.2)$ & 0.82 & $25(25)$ & 0.409 & $10(10.3)$ & 0.062 \\
\hline Gravidity & $46(34.1)$ & 0.104 & $9(7.2)$ & 0.12 & $25(25)$ & 0.138 & $10(10.3)$ & 0.13 \\
\hline Blood group & $46(34.1)$ & 0.802 & $9(7.2)$ & 0.79 & $25(25)$ & 0.921 & $10(10.3)$ & 0.045 \\
\hline Genotype & $46(34.1)$ & 0.31 & $9(7.2)$ & 0.38 & $25(25)$ & 0.054 & $10(10.3)$ & 0.267 \\
\hline Use of ITBN & $46(34.1)$ & 0.02 & $09(6.7)$ & 0.01 & $25(25)$ & 0.021 & $10(10)$ & 0.038 \\
\hline Duration of HIV & $46(34.1)$ & 0.209 & $9(7.2)$ & 0.97 & $25(25)$ & 0.282 & $10(10.3)$ & 0.291 \\
\hline Duration on ARV & $46(34.1)$ & 0.204 & $9(7.2)$ & 0.86 & $25(25)$ & 0.262 & $10(10.3$ & 0.271 \\
\hline
\end{tabular}

Table 3. Summary statistics of the effect of prophylaxis with CTX and SP on Malaria Parasitaemia among study population.

\begin{tabular}{|l|l|l|}
\hline \multirow{2}{*}{ Statistics } & \multicolumn{2}{l|}{ Antimalaria } \\
& \multicolumn{1}{l|}{ CTX } & \multicolumn{2}{l|}{ SP } \\
\hline Parasitaemia (asp/ $\mu$ ) & \multicolumn{2}{l|}{} \\
\hline $\begin{array}{l}\text { Mean paired difference in Parasitaemia before and after } \\
\text { prophylaxis }\end{array}$ & 598 & 381.4 \\
\hline \%Reduction in Parasitaemia & 89.4 & 76 \\
\hline P value of the difference & 0.0000001 & 0.0001 \\
\hline PCV (\%) & & \\
\hline Mean paired difference in PCV before and after prophylaxis & 2.27 & 1.19 \\
\hline \% reduction in PCV & 6.87 & 3.58 \\
\hline P value of difference & 0.015 & 0.154 \\
\hline CD4+ count (cells/ $\mu$ l) & & \\
\hline Mean paired difference in CD4+ count before and after & 54.8 & 49.9 \\
\hline \% difference in CD4+ count & 24.5 & -8.74 \\
\hline P value of difference & 0.00001 & 0.011 \\
\hline
\end{tabular}

cotrimoxazole for prophylaxis in order to detect and treat any possible anaemic tendencies stressed.

\section{References}

1. World Health Organization-WHO (2014) Fact sheet on the world malaria report (2014) Retrieved November 12, 2015, from: www.who.int/malaria/world.mal

2. Grimwade K, French N, Mbatha DD (2004) HIV infection as a cofactor for severe falciparum malaria in adults living in a region of unstable malaria transmission in South Africa. AIDS 18: 547-54.

3. ter Kuile FO, Parise ME, Verhoeff FH, Udhayakumar V, Newman RD, et al. (2004) The burden of coinfection with human immunodeficiency virus type 1 and malaria in pregnant women in sub-Saharan Africa. Am J Trop Med Hyg 71: 41-5.

4. World Health Organization-WHO/UNICEF (2003) The Africa Malaria Report-2003 WHO/CDS/MAL/2003.1093: 24-43.

5. World Health Organization-WHO (2006) Guidelines on co-trimoxazole prophylaxis for HIV infections among children, adolescents and adults in resource-limited settings: recommendations for a public health approach. WHO Geneva: 49pp.
6. World Health Organization-WHO (2010) Bench Aids for the Diagnosis of Malaria infections. 24Pp.

7. Trape JF (1985) Rapid evaluation of malaria parasite density and standardization of thick smear examination for epidemiological investigations. Trans $R$ Soc Trop Med Hyg 79: 181-184.

8. Boisier P, Jambou R, Raharimalala L, Roux J (2002) Relationship between parasite density and fever risk in a community exposed to a low level of malaria transmission in Madagascar highlands. Am J Trop Med Hyg 67: 137-140.

9. World Health Organisation-WHO (2007) Laboratory Guidelines for enumerating CD4 T Lymphocytes in the context of HIV/AIDS. SEA-HLM-392 Distribution: Limited. WHO, New Delhi. 62Pp.

10. Bull BS, Koepke JA, Simson E, van Assendelft OW (2000) Procedure for Determining Packed Cell Volume by the Microhaematocrit method. Approved Standard- Third Edition. Clinical and Laboratory Standard Institute 20: 25Pp

11. Houmsou RS, Wama B, Elkanah SO, Garba LC, Hile TD, et al. (2014) Malaria Infection in HIV Infected Pregnant Women Attending a Rural Antenatal Clinic in Nigeria. Advances in Epidemiology 2014: 6 pp.

12. Panti AA, Omokanye LO, Ekele BA, Jlya NMA, Isah AY, et al. (2012) The prevalence of asymptomatic malaria parasitaemia at delivery in Usmanu Danfodiyo University Teaching Hospital Sokoto North western Nigeria. Global Research Journal of Medical Sciences 2: 048-053.

13. Stephens JK, Ofori MF, Quakyi IA, Wilson ML, Akanmori BD (2014) Prevalence of peripheral blood parasitaemia, anaemia and low birthweight among pregnant women in a suburban area in coastal Ghana. Pan Afr Med J 17: 3. [Crossref]

14. Achidi EA, Kuoh AJ, Minang JT, Ngum B, Achimbom BM, et al. (2005) Malaria infection in pregnancy and its effects on haemoglobin levels in women from a malaria endemic area of Fako Division, South West Province, Cameroon. J Obstet Gynaecol 5: 235-240. [Crossref]

15. Kapito-Tembo A, Meshnick SR, van Hensbroek MB, Phiri K, Fitzgerald M, et al (2011) Marked Reduction in Prevalence of Malaria Parasitemia and Anemia in HIVInfected Pregnant Women Taking Cotrimoxazole With or Without SulfadoxinePyrimethamine Intermittent Preventive Therapy during Pregnancy in Malawi. J Infect Dis 203: 464-472. [Crossref]

16. Colomer J, Colomer C, Gutierrez D, Jubert A, Nolasco A, Donat J, et al. (1990) Anaemia during pregnancy as a risk factor for infant iron deficiency: report from the Valencia Infant Anaemia Cohort (VIAC) study. Paediatr Perinat Epidemiol 4: 196204. [Crossref] 
Ali MA (2017) Impact of prophylaxis with cotrimoxazole on malaria parasitaemia, PCV and CD4+ count in HIV-infected pregnant women in Jos, Nigeria

17. Nokes C, van den Bosch C, Bundy DAP (1998) The effects of iron deficiency and anemia on mental and motor performance, educational achievement and behaviour in children: an annotated bibliography. Washington, D.C.: International Nutritional Anemia Consultative Group;

18. Akinbo FO, Omoregie R (2012) Plasmodium falciparum infection in HIV-infected patients on highly active antiretroviral therapy (HAART) in Benin City, Nigeria. $J$ Res Health Sci 12: 15-18.
19. Tagoe DN, Boachie J (2013) Assessment of the impact of malaria on CD4+ T Cells and haemoglobin levels of HIV-malaria co-infected patients. J Infect Dev Ctries 6: 38-55. [Crossref]

20. Ter Kuile FO, Steketee RW (2007) Intermittent Preventive Therapy with SulfadoxinePyrimethamine during Pregnancy: Seeking Information on Optimal Dosing Frequency. J Infect Dis 196: 1574-1576. [Crossref]

Copyright: $(02017$ Ali MA. This is an open-access article distributed under the terms of the Creative Commons Attribution License, which permits unrestricted use, distribution, and reproduction in any medium, provided the original author and source are credited. 